\title{
El derecho a disposición del otro: Themis y su responsabilidad social
}

\section{ASOCIACIÓN CIVIL THEMIS \\ COMISIÓN DE DESARROLLO SOCIAL DEL CICLO 2010-1*}

Porque la universidad no es una isla que busca librarse de la contaminación ambiental. Es que si no nos contaminamos no estamos en lo nuestro, no estamos en nosotros mismos.

Luis Jaime Cisneros ${ }^{1}$

Quienes realizamos actividades vinculadas al Derecho, según muchos, somos personas sin mayor conciencia social. Muy aparte de si en la práctica dicha valoración es cierta o no, no hay duda respecto a que el Derecho, como ciencia, en nada se opone a una visión socialmente responsable de la realidad. Y es que el Derecho, entendido como instrumento ordenador de la sociedad y generador de cambios sociales, fácilmente puede estar orientado no solo a producir beneficios en favor de quienes lo empleamos, sino también en favor de terceros.

Ahora bien, para que ello suceda es necesario alinear nuestras conductas diarias a la perspectiva de la responsabilidad social y ampliar el espacio social sobre el cual basamos nuestras decisiones, de modo tal que aquellas personas que viven en situación de pobreza queden incluidas en su interior. Sobre dicho cambio, algunas reflexiones y ciertas experiencias vividas por la Asociación Civil Themis tratarán las siguientes líneas.

Actualmente, se puede afirmar que nuestro país está atravesando una serie de transformaciones positivas, lo que se ve reflejado, por ejemplo, en indicadores macroeconómicos ${ }^{2}$. Sin embargo, aunque es importante reconocer dichos avances, es indispensable no dejar a un lado el largo camino que aún nos queda por recorrer. En ese sentido, resulta alarmante por ejemplo que, según las últimas cifras del INEI, el 36,2\% de la población peruana continúe viviendo en situación de pobreza, entendida como aquella situación en la que se vive sin alcanzar el consumo mínimo necesario para satisfacer las necesidades básicas³

* El presente artículo ha sido elaborado por Nicolás de la Flor, Francisco Lira, Cindy Quispe y Andrés Valdivia, quienes han integrado la Comisión de Desarrollo de la Asociación Civil Themis durante el ciclo 2010-1. Las ideas vertidas en el presente artículo reflejan la concepción de responsabilidad social universitaria de la Comisión de Desarrollo de la Asociación Civil Themis.

1 CISNEROS, Luis Jaime. «El ámbito y el sentido de la proyección social». Ponencia presentada en el I Encuentro de Facultades de Derecho sobre Proyección Social, organizado por PROSODE-PUCP en la Pontificia Universidad Católica del Perú.

2 Al respecto, recomendamos leer el siguiente artículo: CUBA, Elmer. «El despegue del Perú» En Luis Pásara (editor). Perú en el siglo XXI. Lima: Fondo Editorial de la Pontificia Universidad Católica del Perú, 2008, pp. 343-361.

3 INEI. «Encuesta nacional de hogares anual 2004-2008». En <http://www1.inei.gob.pe/perucifrasHTM/ inf-soc/cuadro.asp?cod=3773\&name=pob09\&ext=gif $>$. Fecha de consulta: 23 de febrero de 2010 , 23:15 horas. Es importante señalar que, según funcionarios del INEI, a efectos de dichas estadísticas, el consumo mínimo asciende a S/. 251. 
De otro lado, el acceso a la justicia tampoco presenta los indicadores que nos gustaría encontrar. El número de ciudadanos que viven en pobreza legal — definida como la incapacidad de una persona para utilizar los mecanismos de tutela de derechos establecidos a través de normas formales-, debido a distintos factores tales como limitaciones geográficas, económicas y de idioma ${ }^{4}$, es un claro ejemplo de ello5.

Tomando en cuenta esta situación, resulta inevitable preguntarnos icuál es el rol que debemos desempeñar como estudiantes universitarios y, particularmente, como estudiantes de Derecho? Al respecto, consideramos que debemos ser personas caracterizadas por practicar la proyección social $^{6}$, en el sentido de ser agentes de cambio con una clara visión de futuro, sin temor de asumir compromisos que no necesariamente tengan por propósito mejorar nuestra situación, sino que puedan buscar beneficiar a terceros. Ahora bien, un requisito clave para desempeñar dicho rol es el de adaptar la perspectiva de la responsabilidad social universitaria a nuestro estilo de vida.

La responsabilidad social, definida en un principio como la toma de posición, por parte de una determinada empresa, frente a los problemas que la sociedad presenta y frente a su forma de responder ante ellos, surgió como un modo de comprometerlas con el desarrollo de aquellas zonas donde realizaban sus actividades económicas?

Con el paso del tiempo, dicho concepto cobró mayor notoriedad y comenzó a aplicarse en otras áreas. Fue así como llegó al ámbito académico, donde surgió la denominada responsabilidad social universitaria, caracterizada por promover una formación conjunta que implica tanto compromiso académico como compromiso social, a partir de lo cual complementa «el rigor del claustro y el compromiso del mundo exterior ${ }^{8}$. Es decir, busca que la formación universitaria no se quede únicamente en aquel nivel teórico o práctico, que solo podrá afectarnos a nosotros mismos, sino que pretende que proyectemos lo aprendido sobre terceros, en el entendido que «en un país como el nuestro el futuro no llega: se construye, se hace; y no habrá por lo tanto futuro si no lo tomamos en nuestras manos» ${ }^{9}$.

4 DEL MASTRO, Fernando. «Pobreza legal y pobreza extrema legal: ¿quiénes son los responsables?». Themis: Arbitraje, № 53, p. 260, 2006.

5 Al respecto, Del Mastro señala lo siguiente: «En Huancavelica, el departamento más pobre del Perú, no existe siquiera un consultorio jurídico gratuito; en todo el Perú hay alrededor de 304 defensores de oficio, es decir, uno por cada 108,000 peruanos [...]”. Ibíd., p. 260.

6 Para profundizar el tema de la proyección social, sugerimos revisar la ya citada ponencia a cargo del doctor Luis Jaime Cisneros, presentada en el I Encuentro de Facultades de Derecho sobre Proyección Social.

7 Romero Cevallos, Catalina. «Sobre la responsabilidad social en la PUCP». En Responsabilidad Social Universitaria. Blogs PUCP: http://blog.pucp.edu.pe/item/441 . Fecha de consulta: 23 de febrero de 2010, 11:30 horas.

8 LERNER FEBRES, Salomón. «Responsabilidad social de la universidad». En Responsabilidad Social Universitaria. Blogs PUCP: http://blog.pucp.edu.pe/item/441. Fecha de consulta: 23 de febrero de 2010, 11:30 horas.

9 GutiéRREZ, Gustavo. "Qué implica vivir en un país pobre y cómo se ubica la universidad en ese contexto". Lección inaugural del año académico 2007 en la Facultad de Estudios General Letras de la Pontificia Universidad Católica del Perú. 
De lo anterior se desprende, a su vez, que la responsabilidad social universitaria debe ser entendida como el paso siguiente a la labor social. Ello debido a que, si bien ambas implican relacionarse con gente de escasos recursos, la responsabilidad social lleva consigo un elemento volitivo no presente en la labor social, consistente en «querer» entablar dichas relaciones sociales con el propósito de compartir experiencias y de proveer herramientas a quienes no han tenido la posibilidad de obtenerlas por sí solos. En ese sentido, la responsabilidad social busca formar personas que sean «más ciudadanos y menos paternalistas, más reflexivos y no solo emocionales, [busca] articular la ayuda con producción y difusión de conocimientos, etc.» ${ }^{10}$.

En el caso específico de los estudiantes de Derecho, nosotros podemos desarrollarnos desde una perspectiva socialmente responsable, a través de la difusión de información jurídica para personas que viven en situación de pobreza legal, según la definimos anteriormente. De ese modo, buscamos aumentar el acceso a la justicia ${ }^{11} \mathrm{y}$, con ello, la aprobación del sistema legal ${ }^{12}$, así como, en última instancia, democratizarlo.

Estas actividades han sido desarrollados, como ejemplo, por la Asociación Civil Themis, conformada por estudiantes de Derecho y que, desde sus inicios, se ha caracterizado por satisfacer la demanda de diversos sectores por información vinculada con el Derecho. Si bien en un comienzo los productos y los servicios ofrecidos por Themis estuvieron dirigidos a aquellos sectores que ya contaban con cierto conocimiento jurídico, en 2006 la asociación decidió, partiendo de un enfoque de responsabilidad social, ofrecer información legal gratuita a aquellas personas que vivían en situación de pobreza legal.

Por tal motivo, se creó la Comisión de Desarrollo Social, lo que hizo a Themis la primera asociación de estudiantes de Derecho en crear una comisión de este tipo en el país. Si bien dicha decisión implicó una modificación en la estructura de la asociación, ello no representó mayores problemas debido a que Themis concibe el Derecho como un instrumento ordenador de la sociedad, que busca promover la inclusión social a la hora compatibilizar intereses y solucionar conflictos entre distintos sectores sociales. En esa línea, resultó coherente que la propuesta de crear una comisión con la tarea de difundir información legal a gente con escasos recursos no haya presentado mayor oposición.

En particular, las actividades realizadas por la Comisión de Desarrollo Social buscan generar dos grandes cambios. El primero de ellos es empoderar a personas que viven en situación de vulnerabilidad, motivo por

10 VALLAEYS, François. «Responsabilidad social universitaria y voluntariado filantrópico». En Blog de Ética RSU: http://blog.pucp.edu.pe/item/13794. Fecha de consulta: 23 de febrero de 2010, 11:30 horas.

11 LA RoSA CALLE, Javier. «¿Cómo reformar el Poder Judicial incorporando una agenda de acceso a la justicia?». Justicia Viva, 7 de septiembre de 2006, Lima.

12 Según la encuesta realizada por IPSOS APOYO Opinión y Mercado, publicada en el diario El Comercio (A 10) el 20 de abril de 2008, el índice de desaprobación del Poder Judicial llegó a 76\%.

EL DERECHO A DISPOSICIÓN DEL OTRO: THEMIS Y SU RESPONSABILIDAD SOCIAL 
el que se desarrollan talleres de educación legal con ellas, a través de los cuales se les provee de herramientas legales. Por su parte, el segundo gran cambio que se busca se centra más en los miembros de la asociación que en las personas con las cuales desarrollamos las actividades, y tiene por objeto mostrarles a los miembros la gran utilidad que cobra el Derecho para dar solución a los diversos problemas que atraviesan las personas de pocos recursos. En definitiva, lo que se busca con este segundo cambio es mostrar que el Derecho no solo genere beneficios para aquellos con una situación socioeconómica favorable, sino también para quienes no la gozan, en la medida en que los hace menos vulnerables frente a abusos de quienes sí poseen dicho conocimiento, sean del sector privado o del público.

Con ello en mente, la Comisión de Desarrollo Social viene desarrollando sus actividades sobre la base de tres líneas de trabajo. La primera de ellas está orientada a realizar talleres de educación legal, que abarcan distintas materias del Derecho dependiendo de las necesidades del grupo con el que se trabaje. Así, se han realizado desde talleres sobre violencia familiar hasta otros sobre paternidad, siempre con miras no solo a exponer claramente el tema tratado, sino a estar lo suficientemente capacitados como para responder cualquier interrogante que surja durante los talleres.

La segunda línea de trabajo de la comisión ha sido la absolución de consultas legales referidas a casos particulares. Dichas consultas, que por lo general se realizan como complemento de los talleres de educación legal — dado que suelen surgir en ellos-, han recaído mayormente en temas de familia y alimentos.

Por último, la tercera línea de trabajo está referida a la ejecución de proyectos sociales de mayor duración, con el propósito de realizar no solo actividades aisladas sino también capacitaciones integrales, que abarquen distintas materias legales. Al respecto, la mayor experiencia en este campo fue la ejecución del proyecto «La defensoría urbana de José Boterín: una solución democrática contra la violencia familiar» ${ }^{13}$, el cual tuvo por objetivo capacitar a mujeres líderes del asentamiento humano José Boterín en temas vinculados con violencia familiar.

En conclusión, la Asociación Civil Themis apuesta hoy en día por la difusión de la cultura jurídica no solo en las facultades de Derecho o en los estudios de abogados, sino también en los asentamientos humanos, ello debido a que ha logrado comprender que el Derecho no solo debe ser compartido con aquellos que ya se encuentran de algún modo vinculados a la materia, sino también con aquellos que lo desconocen. 